\title{
EMPYEMA THORACIS- A COMPARATIVE ANALYSIS OF TUBERCULOUS AND NON-TUBERCULOUS AETIOLOGY
}

\author{
Tarigopula Pramod Kumar1, G. Ramulu2, M.G. Krishna Murthy33, Prapulla Chandra D4 \\ 1Associate Professor, Department of Pulmonary Medicine, Gandhi Medical College, Secunderabad, Telangana State. \\ ${ }^{2}$ Assistant Professor, Department of Pulmonary Medicine, Gandhi Medical College, Secunderabad, Telangana State. \\ 3 Professor, Department of Pulmonary Medicine, Gandhi Medical College, Secunderabad, Telangana State. \\ ${ }^{4}$ Postgraduate Student, Department of Pulmonary Medicine, Gandhi Medical College, Secunderabad, Telangana State.
}

\begin{abstract}
BACKGROUND
Thoracic empyema is a disease of significant morbidity and mortality, especially in the developing countries like India where tuberculosis remains a common cause. We performed a prospective study over one-and-a-half-year period with the objective of comparing the aetiology, clinical profiles and outcomes of patients with tuberculous and non-tuberculous empyema.

The objective of this study is to study the tuberculous and non-tuberculous patterns in the aetiology of empyema.
\end{abstract}

ABSTRACT

\section{MATERIALS AND METHODS}

This was a prospective observational study of adult patients of non-surgical thoracic empyema admitted in Govt. General and Chest Hospital, Gandhi Medical College, Secunderabad, was performed over a period of 18 months. A comparative analysis of aetiology, clinical characteristics and treatment outcomes of patients with tuberculous and non-tuberculous empyema was carried out.

\section{RESULTS}

52 cases were seen during the study period of which $30(57.7 \%)$ cases were of non-tuberculous aetiology, whereas tuberculosis constitute 22 cases (42.3\%). Among the non-tuberculous aetiology, Gram negative organisms constitute 15 (28.8\%) cases and Gram positive $8(15.3 \%)$ cases. In Tuberculous empyema mean age of presentation was 35.8 years and 44.46 yrs. in nontuberculous empyema. Average duration of symptom presentation in tuberculous and non-tuberculous empyema are 40.35 days and 21.13 days respectively. Mean duration of intercostal tube drainage in tuberculous empyema was 33.55 days vs 18.36 days in non-tuberculous empyema. Bronchopleural fistula was present in $54.54 \%$ of tuberculous versus $20 \%$ of non-tuberculous empyema.

\section{CONCLUSION}

Tuberculous empyema remains a common cause of empyema thoracis in a country like India. Tuberculous empyema differs from non-tuberculous empyema in the age profile, clinical presentation and outcome with earlier presentation, prolonged course of disease and bronchopleural fistula formation requiring surgical intervention. Further studies are needed to evaluate the role of rapid diagnostic tools like CBNAAT with reliable sensitivity and specificity in the diagnostic algorithm for the early diagnosis of tuberculous empyema which would help in planning the treatment of empyema.

\section{KEYWORDS}

Tuberculosis, Non-Tuberculous, Empyema, CBNAAT, Bacteriological Profile, Intercostal Tube Drain (ICTD), AFB-Acid Fast Bacilli, Empyema Thoracis, 1,2 Pyopneumothorax.

HOW TO CITE THIS ARTICLE: Kumar TP, Ramulu G, Murthy MGK, et al. Empyema thoracis- a comparative analysis of tuberculous and non-tuberculous aetiology. Dent. Sci. 2017;6(93):6688-6694, DOI: 10.14260/jemds/2017/1449

\section{BACKGROUND \\ Empyema thoracis 3,4 is defined as collection of pus in the pleural space and has been recognised since the time of Hippocrates and historically has been associated with high mortality. The mortality rate from empyema thoracis remains high and it ranges between $6 \%$ - 24\%. A significant proportion of pleural space infection complicates community or hospital-acquired pneumonia. However, a proportion of pleural space infection results from iatrogenic causes; it is}

'Financial or Other Competing Interest': None.

Submission 26-10-2017, Peer Review 21-11-2017,

Acceptance 27-11-2017, Published 11-12-2017.

Corresponding Author:

Dr. Tarigopula Pramod Kumar,

H. No. 6-2-116 (B-116),

Near Rythu Bazar, Saheb Nagar Kalan,

Vanasthalipuram, Hyderabad- 500 070, Telangana.

E-mail:mdrtbchest8@gmail.com

DOI: $10.14260 /$ jemds $/ 2017 / 1449$

\section{(c)}

also known that pleural infection may develop without pneumonia- so called primary empyema. Empyemas 5,6 are the most common exudative type of pleural effusion.

For centuries, Empyema thoracis has been recognised as a serious problem. The development of antibiotic resistance has also added to the gravity of the condition. The situation has been made worse by the poor economic state and bad hygienic condition in our country.

In developed countries, non-mycobacterial pulmonary infections and surgical procedures constitute the majority of thoracic empyema cases. Staphylococcus and pneumococci are the commonest organisms isolated from the pleural pus. ${ }^{7}$ Rest of the isolates include gram-negative organisms and anaerobes. Gram-negative organisms are frequently isolated, presumably because of high incidence of resistance of these organisms to commonly used antibiotics in the early phase of empyema. More than one isolate was found in many patients and it is well documented. This justifies the use of combination of antibiotics as an empirical form of treatment. 
In the developing world, tuberculosis accounts for a sizeable number. ${ }^{8}$ Clinical outcomes ${ }^{9}$ of tuberculous empyema are generally believed to be worse compared to those of non-tuberculous empyema because of protracted illness, presence of concomitant fibrocavitary lung lesions, high bacillary load, development of bronchopleural fistulae (BPF) and requirement for complicated thoracic surgeries in the context of compromised lung function.

With this scenario in mind, we decided to conduct this study in our tertiary care hospital setup to analyse the clinical course, ${ }^{10}$ bacteriological profile, ${ }^{11}$ various modalities of treatment ${ }^{12,13,14}$ and their outcome in 52 cases of empyema thoracis with tuberculous and non-tuberculous aetiology.

\section{Aims and Objectives}

1. To study the tuberculous and non-tuberculous patterns in the aetiology of Empyema.

2. To compare the age, sex distribution among tuberculous and non-tuberculous groups.

3. To know the effect of early intervention, prognosis, treatment modalities and outcomes in tuberculous and non-tuberculous empyema.

\section{MATERIALS AND METHODS}

This prospective observational study was done on the adult patients with thoracic empyema admitted in the Department of Pulmonary Medicine of Government General and Chest Hospital/ Gandhi Medical College, Hyderabad over a period of 18 months (Dec 2014 - May 2016).

\section{Inclusion Criteria}

1. Clinical features compatible with empyema.

2. All empyema patients, 18 years and above.

3. Chest x-ray appearance of empyema.

\section{Exclusion Criteria}

1. Empyema secondary to penetrating or blunt chest trauma.

2. Empyema secondary to any surgical procedure.

Thoracic empyema ${ }^{15}$ was defined as pleural effusion that fulfilled at least one of the following criteria: - The presence of frank pus on pleural aspiration, presence of organism on pleural fluid culture and positive pleural fluid Gram stain.

Tuberculous empyema was defined as cases of thoracic empyema with one of the following Pleural fluid smears positive for acid fast bacilli (AFB), Sputum positive for AFB and having radiological lesions consistent with active parenchymal tuberculosis on chest x-ray/ CT scan of the thorax (nodular consolidation with or without cavity in apex, tree in bud appearance).

Probable tuberculous empyema was defined as empyema in patients who had radiological evidence of active pulmonary tuberculosis on chest x-ray/ CT scan of the thorax (nodular consolidation with or without cavity in apex, tree in bud appearance) or were sputum positive for AFB.

\section{Assay Method}

Detailed demographic and clinical parameters including age, sex and symptom duration (fever, weight loss, cough, sputum, haemoptysis, shortness of breath, chest pain) were evaluated in all patients fulfilling the case definition. Presence of any comorbidities like diabetes mellitus, hypertension, past history of pulmonary Koch's, HIV infection and malignancy was documented. Chest radiographs were obtained in all patients at the time of admission after intercostal tube drain (ICTD) insertion, ICTD removal and at discharge, while ultrasound (USG) and computed tomography (CT) of chest were done if necessary.

\section{Collection of Samples and Procedure}

Pleural fluid was collected aseptically by thoracocentesis and if macroscopically purulent was submitted for Gram stain, culture (aerobic) and smear for AFB. Complete blood counts, renal and liver function tests, blood for HIV serology under voluntary basis, blood sugar (fasting and postprandial) and sputum for AFB smear were sent in for all patients.

Aetiology of empyema was decided based on history, physical examination, radiology 6 and empyema fluid analysis. ${ }^{16}$ BPF was diagnosed if chest $\mathrm{x}$-ray prior to thoracocentesis revealed horizontal air fluid level in the upright position and air leak through the tube thoracostomy persisted for more than 24 hours after tube thoracostomy.

Closed tube thoracostomy (intercostal tube drainage, ICTD) was carried out with a straight chest tube (Romson 28 - 32 F) attached to a water-seal drainage system. Continuous drainage was maintained until fluid was serous, daily collection was less than $50 \mathrm{~mL}$ for 3 consecutive days, pleural cavity was obliterated by expansion of the lung and any BPF was sealed.

In cases of multiloculated empyema as serial ultrasound-guided aspiration of pleural fluid was done. All patients with non-tuberculous empyema received antibiotics for a total duration of 4 - 6 weeks depending on clinical response. For the initial 14 days, intravenous antibiotics were administered followed by oral antibiotics. Empirical antibiotics chosen in this study were a thirdgeneration cephalosporin plus metronidazole for anaerobic coverage. Antibiotic regimen was changed subsequently if culture sensitivity reported resistant organisms. Aminoglycosides were not used because of their low concentration in pus.

All patients of tuberculous empyema received category I or category II antituberculous drugs (ATT) treatment under DOTS strategy of RNTCP. In addition, they were initially kept on intravenous antibiotics and further course of which was determined by Gram stain/ culture report and clinical response. Use of intrapleural fibrinolytics ${ }^{17}$ was not included in the study. In those patients who failed to respond to antibiotic therapy and ICTD (after checking for clogged tubes, incorrect tube placement) as evidenced by the persistence of fever or leukocytosis due to loculations or inadequate drainage, non-expansion of the lung or the presence of BPF were subjected to surgical management in the cardiothoracic department of the institute. Decortication, decortication with closure of BPF using intercostal muscle flap were the surgical procedures performed.

All the patients were advised for follow-up at 1 and 3 months. Those who came for follow-up were assessed for lung expansion and deformities of the chest wall by clinical 
examination and chest x-ray if necessary. Ethical clearance was obtained for this study.

Aetiology of empyema thoracis in all the 52 patients was decided based on history, physical examination, radiology and empyema fluid analysis as TB and Non-TB empyema. The data was analysed on age, gender distribution, duration of symptoms, associated conditions, bacteriological profile and management of cases and their outcome. Statistical analysis was performed using GraphPad Prism (v 5.03) software. Chi-square test was used to compare data sets. All comparisons were considered significant if the $\mathrm{p}$ value was $\leq 0.05$.

Statistical Analysis and Descriptive Values: The data has been analysed as below

\begin{tabular}{|c|c|c|}
\hline Age & No. of Cases & Percentage \\
\hline $18-20$ & 03 & $5.7 \%$ \\
\hline $21-30$ & 13 & $25 \%$ \\
\hline $31-40$ & 14 & $27 \%$ \\
\hline $41-50$ & 08 & $15.3 \%$ \\
\hline $51-60$ & 11 & $21 \%$ \\
\hline$>60$ & 03 & $06 \%$ \\
\hline Total & $\mathbf{5 2}$ & $\mathbf{1 0 0} \%$ \\
\hline \multicolumn{2}{|c|}{ Table 1. Age Distribution of Empyema }
\end{tabular}

Table 1 shows majority of the cases were in the age group of 31 - 40 years ( $4^{\text {th }}$ decade) consisting of $14(27 \%)$ patients followed by 21 - 30 years' age group constituting $25 \%$ of the patients. Together 21 - 40 years' age group constituted majority of the cases nearing 52\%. Youngest patient was 18 years and oldest was of 75 years.

\begin{tabular}{|c|c|c|}
\hline Sex & No. of Cases & Percentage \\
\hline Male & 41 & $79 \%$ \\
\hline Female & 11 & $21 \%$ \\
\hline Total & $\mathbf{5 2}$ & $\mathbf{1 0 0 \%}$ \\
\hline \multicolumn{2}{|c|}{ Table 2. Gender Distribution } \\
\hline
\end{tabular}

Table 2 shows the male predominance in the distribution of cases with $79 \%$ of total.

\begin{tabular}{|c|c|c|}
\hline Condition & No. of Cases & Percentage \\
\hline Diabetes & 10 & $19.2 \%$ \\
\hline Hypertension & 06 & $11.5 \%$ \\
\hline Smoking & 19 & $37 \%$ \\
\hline HIV & 04 & $7.6 \%$ \\
\hline Postpartum & 01 & $02 \%$ \\
\hline \multicolumn{2}{|c|}{ Table 3. Associated Conditions } \\
\hline
\end{tabular}

Table 3 shows smoking was the most commonly associated condition with empyema cases in the present study seen in 19 (37\%) cases. Diabetes mellitus was associated in 10 (19\%) cases; 6 patients were hypertensive on antihypertensive drugs. The present study showed the association of HIV with empyema in 4 cases. One patient presented in 1 week postpartum period with empyema.

\begin{tabular}{|c|c|c|}
\hline & No. of Cases & Percent \\
\hline TB & 22 & $42.30 \%$ \\
\hline Non-TB & 30 & $57.70 \%$ \\
\hline Total & $\mathbf{5 2}$ & $\mathbf{1 0 0} \%$ \\
\hline \multicolumn{2}{|c|}{ Table 4. No. of TB and Non-TB Cases }
\end{tabular}

Table 4 shows among the 52 patients, 22 empyema cases were diagnosed to be of tuberculous aetiology constituting $42.30 \%$ and the remaining 30 (57.70\%) cases were of non-tuberculous aetiology.

\begin{tabular}{|c|c|c|c|c|}
\hline Duration & TB & Percent & Non-TB & Percent \\
\hline$<10$ Days & 0 & $0 \%$ & 2 & $6 \%$ \\
\hline 11-20 Days & 2 & $9 \%$ & 12 & $40 \%$ \\
\hline 20-30 Days & 7 & $32 \%$ & 15 & $50 \%$ \\
\hline$>1$ Month & 13 & $59 \%$ & 01 & $4 \%$ \\
\hline Total & 22 & $100 \%$ & $\mathbf{3 0}$ & $\mathbf{1 0 0} \%$ \\
\hline \multicolumn{5}{|c|}{ Table 5. Duration of Symptoms } \\
\hline
\end{tabular}

$\mathrm{P}=0.0000001$, Chi-Square $=18.83$

Table 5 shows that tuberculous empyema patients presented late with symptoms usually after 1 month when compared with non-tuberculous empyema patients who presented early with the disease. Majority of the patients, 13 (59\%) with TB empyema presented with more than 1 month duration which was statistically significant; 2 cases with non-tuberculous aetiology presented with less than 10 days duration with most presenting with 10 - 20 days duration nearly $90 \%$ of non-tuberculous cases.

\begin{tabular}{|c|c|c|}
\hline & Duration in Days & SD \\
\hline TB & 40.35 days & 14.34 \\
\hline Non-TB & 21.13 days & 14.35 \\
\hline \multicolumn{3}{|c|}{ Table 6. Mean Duration of Symptoms } \\
\hline
\end{tabular}

P value 0.000001

Table 6 shows the mean duration of symptoms in tuberculous empyema was 40.35 days, whereas in non-TB empyema it was 21.13 days. This was statistically significant.

\begin{tabular}{|c|c|c|c|c|}
\hline Age & TB & Percentage & Non-TB & Percentage \\
\hline $18-20$ & 1 & $4.5 \%$ & 2 & $6.66 \%$ \\
\hline $21-30$ & 10 & $45.45 \%$ & 3 & $10 \%$ \\
\hline $31-40$ & 6 & $27.27 \%$ & 8 & $26.66 \%$ \\
\hline $41-50$ & 1 & $4.5 \%$ & 7 & $23.33 \%$ \\
\hline $51-60$ & 3 & $13.63 \%$ & 8 & $26.66 \%$ \\
\hline$>60$ & 1 & $4.5 \%$ & 2 & $6.66 \%$ \\
\hline Total & $\mathbf{2 2}$ & $\mathbf{1 0 0} \%$ & $\mathbf{3 0}$ & $\mathbf{1 0 0} \%$ \\
\hline
\end{tabular}

Chi-square $=7.21, \mathrm{P}$ value $=0.03, \mathrm{df}=1$

Table 7 shows majority (17) patients of TB Empyema were less than 40 years. Only (5) patients were more than 40 years and that was statistically significant. The present study highlighted that TB empyema cases were seen commonly in younger age group, whereas non-TB cases in middle age and old age groups. $73 \%$ of the TB cases were in 21 - 40 years' age group, whereas $75 \%$ of non-TB cases were in 31 - 60 years' age group. Mean age of presentation was 35.8 years in TB aetiology and 44.46 years in non-TB aetiology.

\begin{tabular}{|c|c|c|c|c|}
\hline Gender & TB & Percent & Non-TB & Percent \\
\hline Male & 17 & $77.27 \%$ & 24 & $80 \%$ \\
\hline Female & 5 & $22.73 \%$ & 6 & $20 \%$ \\
\hline Total & $\mathbf{2 2}$ & $\mathbf{1 0 0} \%$ & $\mathbf{3 0}$ & $\mathbf{1 0 0} \%$ \\
\hline \multicolumn{6}{|c|}{ Table 8. Gender Distribution in TB and Non-TB } \\
\hline
\end{tabular}

Chi-square $=0.08, \mathrm{P}$ value $=0.81$ 
Table 8 shows there was no significant difference in TB and non-TB cases with male and female sex distribution with both showing male predominance in nearly $80 \%$ cases and it was statistically not significant.

\begin{tabular}{|c|c|c|c|c|}
\hline & TB & Percentage & Non-TB & Percentage \\
\hline Smoking & 08 & $36.36 \%$ & 11 & $36.66 \%$ \\
\hline Diabetes & 06 & $27.27 \%$ & 04 & $13.33 \%$ \\
\hline Hypertension & 02 & $09.09 \%$ & 04 & $13.33 \%$ \\
\hline Past H/O PTB & 12 & $54.54 \%$ & 03 & $10.0 \%$ \\
\hline HIV & 03 & $13.63 \%$ & 01 & $3.33 \%$ \\
\hline Postpartum & 00 & $00.00 \%$ & 01 & $3.33 \%$ \\
\hline \multicolumn{6}{|c|}{ Table 9. Associated Conditions in TB and Non-TB } \\
Empyema
\end{tabular}

Chi-square $=3.44, \mathrm{df}=5, \mathrm{P}$ value $=0.63$

Table 9 shows smoking was associated with 8 (36\%) cases of tubercular group and $11(36 \%)$ cases of nontubercular group. Diabetes (27\%) and HIV (14\%) association were higher in TB group than non-TB group; 12 (55\%) patients of TB empyema had history of tuberculosis; $3(10 \%)$ cases of non-TB empyema had past h/o tuberculosis, but presented with acute duration and were positive for organisms on pleural fluid gram staining and resolved with antibiotics. One case of non-tubercular empyema presented in postpartum period.

\begin{tabular}{|c|c|c|}
\hline Organisms & No. of Cases & Percentage \\
\hline $\mathrm{GM}+\mathrm{VE}$ & 08 & $15.3 \%$ \\
\hline $\begin{array}{l}\text { Streptococcus } \\
\text { pneumoniae }\end{array}$ & 02 & $3.8 \%$ \\
\hline $\begin{array}{c}\text { Staphylococcus } \\
\text { aureus }\end{array}$ & 04 & $7.5 \%$ \\
\hline Enterococcus & 01 & $02 \%$ \\
\hline Micrococci & 01 & $02 \%$ \\
\hline GM -ve & 15 & $28.8 \%$ \\
\hline Pseudomonas & 04 & $7.5 \%$ \\
\hline Klebsiella & 06 & $11.5 \%$ \\
\hline E. coli & 01 & $02 \%$ \\
\hline Enterobacter & 01 & $02 \%$ \\
\hline Proteus & 01 & $02 \%$ \\
\hline Multiple Organisms & 02 & $3.8 \%$ \\
\hline $\mathrm{AFB}+\mathrm{ve}$ & 06 & $11.5 \%$ \\
\hline Sterile & 23 & $44.2 \%$ \\
\hline
\end{tabular}

Table 10 shows pleural fluid showed no organism in $44 \%$ of cases, i.e. 23 patients. Bacteriological isolation was done in $29(56 \%)$ cases. Among those isolated, majority were gram negative $15(29 \%)$ cases. Klebsiella sp. (11\%) was the most common gram-negative organism isolated followed by pseudomonas (8\%), E. coli, Enterobacter and Proteus constituting 1\% each. Gram positive organisms were detected in $8(15 \%)$ patients with Staph. aureus in $4(8 \%)$ cases followed by streptococci in $4 \%$ cases; 2 cases showed polymicrobial variety with Klebsiella and Proteus. AFB stain was positive in $6(12 \%)$ cases.

\begin{tabular}{|c|c|c|c|c|}
\hline & ADA (Mean) & SD & Protein (Mean) & SD \\
\hline TB & 92.38 & 37.16 & 5.6 & 36.82 \\
\hline Non-TB & 59.11 & 2.17 & 5.38 & 2.19 \\
\hline \multicolumn{5}{|c|}{ Table 11. Pleural Fluid Analysis } \\
\hline
\end{tabular}

Table 11 shows Tubercular empyema had pleural fluid ADA mean value of 92.38 and protein mean value of 5.6, whereas non-tubercular pleural fluid showed mean ADA value of 59.11 and protein value of 5.38. Both groups showed PMN predominance in pleural fluid.

\begin{tabular}{|c|c|c|}
\hline & No. of Cases & Percentage \\
\hline Sputum +ve & 12 & $54.54 \%$ \\
\hline PL. Fluid AFB +ve & 06 & $27.27 \%$ \\
\hline Past H/O PTB & 12 & $54.54 \%$ \\
\hline Infiltrates on CXR & 08 & $36.36 \%$ \\
\hline \multicolumn{2}{|c|}{ Table 12. Diagnostic Criteria for TB Empyema } \\
\hline
\end{tabular}

Table 12 shows out of 22 patients diagnosed as having tubercular empyema, the diagnosis was established bacteriologically with AFB isolated in pleural fluid in 6 (27\%) cases and sputum AFB +ve in 12 (54.54\%) cases. In the remaining cases, the diagnosis was based on past history of tuberculosis, radiological appearances consistent with active tuberculosis.

\begin{tabular}{|c|c|c|c|c|}
\hline & TB & Percent & Non-TB & Percent \\
\hline ICD & 18 & $81.81 \%$ & 22 & $73.33 \%$ \\
\hline Thoracentesis & 04 & $19.19 \%$ & 08 & $26.64 \%$ \\
\hline \multicolumn{6}{|c|}{ Table 13. Treatment Modalities in TB and Non-TB } \\
Cases \\
\hline
\end{tabular}

Chi-square $=0.50, \mathrm{df}=1, \mathrm{P}$ value $=0.42$

Table 13 shows the drainage modalities in nontuberculous empyema were intercostal tube drainage in 22 $(73 \%)$ cases and thoracocentesis in $8(27 \%)$ cases. In tuberculous empyema, intercostal drainage in 18 (82\%) cases and serial aspirations in 4 (19\%) cases.

\begin{tabular}{|c|c|c|c|c|c|}
\hline & TB & SD & Non-TB & SD & P value \\
\hline $\begin{array}{c}\text { Mean Duration } \\
\text { of ICD }\end{array}$ & $\begin{array}{c}32.49 \\
\text { Days }\end{array}$ & 12.49 & $\begin{array}{c}18.36 \\
\text { Days }\end{array}$ & 12.34 & 0.0001 \\
\hline BPF & $12(54.54 \%)$ & & $06(20 \%)$ & & 0.004 \\
\hline Resolution & $13(59 \%)$ & & $\begin{array}{c}25 \\
(83.33 \%)\end{array}$ & & 0.04 \\
\hline Surgery & $04(18.18 \%)$ & & $\begin{array}{c}01 \\
(3.33 \%)\end{array}$ & & 0.03 \\
\hline \multicolumn{7}{|c|}{ Table 14. ICD Tube Drainage and Outcome } \\
\hline
\end{tabular}

Table 14 shows Mean duration of ICD tube drainage was higher in tubercular group (32.5 days) as against the nontubercular group (12.34 days) with $P$ value of 0.0001 , which means it was statistically significant. BPF was seen in 12 (54.54\%) cases of tubercular group and $6(20 \%)$ cases of non-tubercular group. P value for BPF was 0.004 and it was significant. Good lung expansion with minimal or no pleural thickening was the outcome in $25(83.33 \%)$ cases of nontuberculous empyema and only 13 (59\%) cases of tubercular empyema; 4 cases of tubercular and 1 case of non-tubercular empyema underwent decortication. One patient of tubercular empyema succumbed to death.

\section{DISCUSSION}

Thoracic empyema continues to be an important cause of morbidity, especially in developing countries and this has been reflected in the present study by the number of cases enrolled (52 over an 18-month period). Pulmonary infections (including community acquired pneumonia, bronchiectasis 
and lung abscess) are the commonest cause of thoracic empyema in the western countries followed by surgical trauma. In contrast, studies from India reveal that tuberculosis accounts for a large number of empyema cases $(38.6 \%$ - 65\%). In the present study also, tuberculous empyema accounted for 22 out of 52 cases, i.e. $42.30 \%$ of total empyema cases. The high incidence of empyema in the productive age group of 21 - 40 years in the present study is consistent with the findings in the earlier studies by Acharya et al,18 S Kundu, Behra and Tandon. ${ }^{19}$

In the study by MV Vardhan, SC Tewari, BNBM Prasad and SK Nikumb et al ${ }^{20}$ also, most cases were of the age group 21 40 years comparable with the present study. This reiterates that most of the patients effected were of younger age group and males i.e. economically productive age group being affected and this was in line with the fact that tuberculosis is the major cause for empyema which usually affects younger male population.

In the present study, males outnumbered female patients as seen in other studies. Males in general are more prone to mechanical stresses due to their tall stature and strenuous work. Smoking is a more frequent habit and tuberculosis and COPD are more frequent in males. Hence, the disease seems to be more common in males and the results of these studies are all comparable to that of the present study.

In a study by MV Vardhan and SC Tewari et al published in Indian TB Journal 1998, smoking association was comparable with the present study. Smoking association is almost equal in both the tuberculous and non-tuberculous groups. Association of Diabetes and TB with empyema were higher in the present study and it was more common in tuberculous empyema.

According to S Kundu et al and present study, majority of tuberculous empyema cases belonged to a relatively younger age group (18 - 40 years), non-tuberculous empyema patients were above 45 years of age. Mean age of presentation in tuberculous empyema in the present study was 35.8 years comparable with that of Kundu study (32.7 years), whereas in non-tuberculous aetiology it was 44.46 years in the present study and 46.5 years in Kundu study.

Majority cases of tuberculous empyema had more than 1 month duration presentation, whereas only few cases of nontuberculous empyema had duration of more than 1 month and mean duration of illness was significantly higher in tuberculous group compared to non-tuberculous group.

In the present study, many cases were sterile 23 (44.2\%). Bacteriological isolation was seen in 29 (55.8\%) cases. Majority 15 (28.8\%) were showing gram negative organisms. Among the gram-negative organisms, Klebsiella sp. 6 (11.5\%) were the commonest organism isolated followed by Pseudomonas 4 (7.5\%), E. coli $1(2 \%)$, Proteus $1(2 \%)$ and Enterobacter 1 (2\%). AFB was isolated in $6(11.5 \%)$ cases. This negative culture report in present series was related with good number of tuberculous empyema and anaerobic organisms. Mycobacteria and anaerobic organisms do not grow on ordinary media.

\begin{tabular}{|c|c|c|c|}
\hline Organisms & $\begin{array}{c}\text { Acharya } \\
\text { et al18 }\end{array}$ & $\begin{array}{c}\text { Study of } \\
\text { Anil Gupta }\end{array}$ & $\begin{array}{c}\text { Present } \\
\text { Study }\end{array}$ \\
\hline Staphylococci & $12.5 \%$ & $16 \%$ & $7.5 \%$ \\
\hline Streptococci & 0 & $2 \%$ & $3.8 \%$ \\
\hline Pseudomonas & $17.5 \%$ & $22 \%$ & $7.5 \%$ \\
\hline
\end{tabular}

\begin{tabular}{|c|c|c|c|}
\hline E. coli & $5 \%$ & $12 \%$ & $2 \%$ \\
\hline Klebsiella & $2.5 \%$ & $2 \%$ & $11.5 \%$ \\
\hline Mixed flora & $0.5 \%$ & 0 & $3.8 \%$ \\
\hline $\begin{array}{l}\text { Mycobacterium } \\
\text { tuberculosis }\end{array}$ & $15 \%$ & 0 & $11.5 \%$ \\
\hline Sterile & $47 \%$ & $46 \%$ & $44.2 \%$ \\
\hline
\end{tabular}

The organisms isolated in the present study were comparable to that of the above-mentioned studies, except that Klebsiella was predominant. Gram negative organism was isolated in the present study, whereas other studies report pseudomonas as predominant organism. Sterile results were comparable with the other studies.

TB empyema has been diagnosed on the basis of empyema with the presence of pleural fluid smear positive for AFB bacilli, sputum smear AFB positive and having radiological lesions consistent with active pulmonary tuberculosis or having past history of pulmonary TB.

\begin{tabular}{|c|c|c|c|}
\hline & $\begin{array}{c}\text { Kundu } \\
\text { Studyo8 }\end{array}$ & $\begin{array}{c}\text { Acharya } \\
\text { Study } 18\end{array}$ & $\begin{array}{c}\text { Present } \\
\text { Study }\end{array}$ \\
\hline Sputum +ve & $19(65.5 \%)$ & $10(25 \%)$ & $\begin{array}{c}12 \\
(54.54 \%)\end{array}$ \\
\hline Pl. fluid AFB +ve & $27(93.1 \%)$ & $12(30 \%)$ & $\begin{array}{c}06 \\
(27.27 \%)\end{array}$ \\
\hline Past H/O PTB & ---- & $18(36 \%)$ & $\begin{array}{c}12 \\
(54.54 \%)\end{array}$ \\
\hline Infiltrates on CXR & $20(68.1 \%)$ & & $\begin{array}{c}08 \\
(36.36 \%)\end{array}$ \\
\hline \multicolumn{3}{|r|}{ Table 16. Diagnosis of TB Empyema } \\
\hline
\end{tabular}

In Kundu study, 08 more number of cases showed pleural fluid smear for AFB positive (93\%). But other studies like Acharya study, ${ }^{18}$ Vardhan study showed less positive cases which were comparable with the present study. Sputum positivity for AFB was comparable among all the studies along with the present study. In Acharya et al study pleural fluid AFB was positive in $30 \%$ cases, which was comparable with that of present study (27\%). Past history of TB was observed in 36\% cases in Acharya study, whereas it was 55\% in the present study and most of them were defaulters.

\section{Pleural Fluid Analysis}

Frank pus was seen in 46/52 (88.4\%) of the cases and 6/52 (11.6\%) had seropurulent effusion. Tubercular empyema patients had mean ADA value of $92.38 \mathrm{IU} / \mathrm{dL}$ and mean protein $5.6 \mathrm{mg} / \mathrm{dL}$, while mean ADA was $59.11 \mathrm{IU} / \mathrm{dL}$ in nontubercular cases, mean protein was $5.38 \mathrm{mg} / \mathrm{dL}$. In both tubercular and non-tubercular cases, PMN were predominant.

\section{Treatment and Outcome}

In the present study $81 \%$ of the tubercular cases and $73 \%$ of the non-tubercular group underwent tube thoracostomy, which were comparable with those of Kundu study and repeated aspirations were done in $19 \%$ of tubercular and $26 \%$ of non-tubercular empyema. In the present study, $80 \%$ of the cases were managed with intercostal tube drainage. Despite being recognised since the ancient times, the appropriate management of empyema remains controversial. 
It may be postulated that the most appropriate therapy depends on the stage of the disease at presentation.

The literature provides many options including antibiotics alone or in combination with repeated thoracentesis, closed intercostal tube drainage, fibrinolytic agents like streptokinase or deoxyribonuclease, videoassisted thoracoscopy, thoracotomy and decortication.

In the present study, 40/52 (80\%) were managed with ICD and antibiotics. Amount of pus drained was $1500-4000$ $\mathrm{mL} ; 90 \%$ of the pleural drain occurred on the first 3 days. Minimum duration for lung expansion was seven days and maximum was 45 days.

Mean duration of intercostal tube drainage was also higher in the tubercular group (32.49 days) as against the non-tubercular group (18.3 days) in the present study. When compared with Kundu study, mean duration of ICD was 48.7 days and 23.2 days in tubercular and non-tubercular groups respectively. It suggests that tuberculous empyema has more chronicity not only in terms of symptom presentation, but also treatment course.

In the present study, Broncho Pleural Fistula (BPF) was seen in $12(54.54 \%)$ cases of tubercular and $6(20 \%)$ cases of non-tubercular empyema. In Kundu ${ }^{08}$ study, 16 (55.2\%) cases of tubercular and $5(10.9 \%)$ cases of non-tubercular groups presented with bronchopleural fistula indicating that tuberculous empyema had bad prognosis when compared with the other group requiring surgical management.

Progression of the empyema with the development of fibrinous adhesions and loculations make simple drainage difficult if not impossible. Chest tube drainage and intravenous antibiotic therapy might be adequate for stage 1 empyema. However, this approach is rarely effective in patients with stage 2 or 3 disease.

Although, there might be clinical improvement with drainage of the pleural space and antibiotic therapy, reexpansion of the entrapped lung is unlikely to occur in a significant number of cases and this ultimately leads to surgical intervention. Recognising the limitations to this approach, some researchers have advocated the use of intrapleural fibrinolytic agents as a form of chemical debridement to enhance pleural drainage and to disrupt loculations. The study by Rahman et al "Intrapleural use of tissue plasminogen activator and DNase in pleural effusion" showed that intrapleural t-PA and DNase therapy improved the fluid drainage and reduced the frequency of surgical referral and hospital stay. ${ }^{17}$

Good lung expansion with minimal pleural thickening was seen in $25(83.33 \%)$ cases of non-tubercular cases. But only 13 (59\%) cases of tubercular empyema had resolution. Four patients with tuberculous empyema underwent surgery despite ATT and ICTD, whereas only one (3.33\%) in the nontuberculous group needed surgery. These results were comparable with those of Kundu study.

The outcome among tuberculous and non-tuberculous groups of empyema were different with non-tuberculous empyema showing good response and almost complete resolution in most cases with appropriate antibiotics and therapeutic procedures like serial thoracocentesis and intercostal drainage. But in tubercular group, despite ATT and ICDT, the duration and course of the disease was longer, hospital stay and mean duration of ICDT was longer with more cases presenting with BPF and resolution rate was less compared to non-tubercular group.

\section{Follow-Up}

All patients were followed up after the discharge at 1 and 3 months. All of them were evaluated clinically and radiographically. Most of the patients (68\%) were asymptomatic and had good lung expansion; $12 \%$ were clinically normal, but revealed pleural thickening; $11 \%$ had persistent collapse.

\section{CONCLUSION}

- Empyema continues to be prevalent in our country, particularly in the lower socioeconomic strata due to the delay in seeking medical care, inappropriate antibiotics and dosages and duration of antibiotic treatment.

- Empyema fluid is diagnostic for pathogens if appropriate handling and early cultures were done, but in the present scenario with prior antibiotic treatment the fluid is sterile in most cases. Pleural fluid biochemical parameters would also vary depending on the stage of empyema, severity and previous antibiotic therapy.

- Management of primary empyema continues to be controversial in terms of duration of antibiotic therapy and the indications for and timing of surgery. There is a need for randomised controlled trial for strict guidelines on the management of empyema.

- Tuberculous empyema differs from non-tuberculous empyema in the age profile, clinical presentation, management issues and has a significantly poorer outcome.

- Tuberculous empyema remains a significant cause of empyema thoracis in India. Further studies are needed to evaluate the role of rapid diagnostic tools like CBNAAT with reliable sensitivity and specificity in the diagnostic algorithm for the early diagnosis of tuberculous empyema, which would help in planning the treatment of empyema.

\section{ACKNOWLEDGEMENT}

The Author sincerely acknowledges and thanks Dr. MG Krishna Murthy, Professor and Head of the Department of Pulmonary Medicine, Gandhi Medical College, Secunderabad/ Government General and Chest Hospital, TS, for the cooperation and their assistance during the study.

\section{REFERENCES}

[1] Brook I, Frazier EH. Aerobic and anaerobic microbiology of empyema. A retrospective review in two military hospitals. Chest 1993;103(5):1502-7.

[2] Light RW. Parapneumonic effusions and empyema. In: Light RW. edr. Pleural diseases. 3rd edn. Baltimore: Williams and Wilkins 1995:129,153.

[3] Acharya PR, Shah KV. Empyema thoracis: a clinical study. Ann Thorac Med 2007:2(1):14-7.

[4] Gupta SK, Kishan J, Singh SP. Review of one hundred cases of empyema thoracis. Indian J Chest Dis Allied Sci 1989;31(1):15-20.

[5] King S, Thomson A. Radiological perspectives in empyema. Br Med Bull 2002;61:203-14. 
[6] Silverman SG, Mueller PR, Saini S, et al. Thoracic empyema management with image-guided catheter drainage. Radiology 1988;169(1):5-9.

[7] Light RW. Parapneumonic effusions and empyema. In: Light RW. edr. Pleural diseases. 3rd edn. Baltimore: Williams and Wilkins 1995:129,153.

[8] Kundu S, Mitra S, Mukherjee S, et al. Adult thoracic empyema: a comparative analysis of tuberculous and non-tuberculous etiology in 75 patients. Lung India 2010;27(4):196-201.

[9] Murphy D, Lockhart CH, Todd JK. Pneumococcal empyema: outcome of medical management. Am J Dis Child 1980;134(7):659-62.

[10] Ferguson AD, Prescott RJ, Selkon JB, et al. The clinical course and management of thoracic empyema. QJM 1996;89(4):285-9.

[11] Porcel J, Vázquez P, Vives M, et al. Manonelles Pleural Space Infections: microbiologic and fluid characteristics in 84 patients. The Internet Journal of Pulmonary Medicine 2003;3(1):1-5.

[12] Gupta A, Dutt N, Patel N. The different treatment modalities of pyopneumothorax. A study of 50 cases. IND J Med Sci Pub Health 2013;2(3):609-12.
[13] Neff CC, Van Sonnenberg E, Lawson DW, et al. CT follow-up of empyemas: pleural peels resolve after percutaneous catheter drainage. Radiology 1990;176(1):195-7.

[14] Hamm H, Light RW. Parapneumonic effusion and empyema. Eur Respir J 1997;10(5):1150-6.

[15] Seaton A, Seaton D, Leitch AG. Empyema. Crofton and Douglas's respiratory diseases. $5^{\text {th }}$ edn. UK: Blackwell Sciences 2000:450.

[16] Benfield GF. Recent trends in empyema thoracis. Br J Dis Chest 1981;75(4):358-66.

[17] Rahman NM, Maskell NA, West A, et al. Intraplueral use of tissue plasmiogen activator and DNase in plueral infections. N Eng J Med 2011;365:518-26.

[18] Light RW, Girard WM, Jenkinson SG, et al. Parapneumonic effusion. Ann J Med 1980;69(4):50712.

[19] Tandon RK, Misra OP. Clinicaopathological study of thoracis empyema and evaluation of its surgical treatment. Indian J Chest Dis 1974;16(1):21-30.

[20] Lin YC, Tu CY, Chen W, et al. An urgent problem of aerobic gram-negative pathogen infection in complicated parapneumonic effusions or empyemas. Intern Med 2007;46(15):1173-8. 